Knowledge Integration

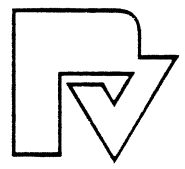


Antonie Jetter - Jeroen Kraaijenbrink Hans-Horst Schröder - Fons Wijnhoven (Editors)

\section{Knowledge Integration}

The Practice of Knowledge Management in Small and Medium Enterprises

With 53 Figures and 24 Tables

Physica-Verlag

A Springer Company 
Dr. Antonie Jetter

Professor Dr. Hans-Horst Schröder

Chair for Business Administration

with Focus on Technology and Innovation Management (TIM)

RWTH Aachen University

Templergraben 64

52056 Aachen

Germany

jetter@tim.rwth-aachen.de

schroeder@tim.rwth-aachen.de

Jeroen Kraaijenbrink

Professor Dr. Fons Wijnhoven

University of Twente

School of Business,

Public Administration and Technology

P.O. Box 217

Drienerlolaan 5

7500 AE Enschede

The Netherlands

j.kraaijenbrink@utwente.nl

a.b.j.m.wijnhoven@utwente.nl

ISBN-10 3-7908-1586-1 Physica-Verlag Heidelberg New York

ISBN-13 978-3-7908-1586-3 Physica-Verlag Heidelberg New York

Cataloging-in-Publication Data applied for

Library of Congress Control Number: 2005934345

This work is subject to copyright. All rights are reserved, whether the whole or part of the material is concerned, specifically the rights of translation, reprinting, reuse of illustrations, recitation, broadcasting, reproduction on microfilm or in any other way, and storage in data banks. Duplication of this publication or parts thereof is permitted only under the provisions of the German Copyright Law of September 9, 1965, in its current version, and permission for use must always be obtained from Physica-Verlag. Violations are liable for prosecution under the German Copyright Law.

Physica is a part of Springer Science+Business Media

springeronline.com

(C) Physica-Verlag Heidelberg 2006

Printed in Germany

The use of general descriptive names, registered names, trademarks, etc. in this publication does not imply, even in the absence of a specific statement, that such names are exempt from the relevant protective laws and regulations and therefore free for general use.

Cover-Design: Erich Kirchner, Heidelberg

SPIN 11423379

43/3153-5 432210 - Printed on acid-free paper 


\section{Preface}

Imagine Measure \& Co, a two-person company creating optical measurement instruments for the graphical industry. Mark, the owner and founder of Measure \& Co has a thorough background in measurement technology and has worked for years on his own. Lately, he has found a partner, Susan, who is experienced in commercial and marketing activities and takes care of customer relations and sales.

Although Mark and Susan together possess much of the knowledge that is needed to run their company, it is by far not sufficient. They need to stay informed about new measurement technologies, changing customer demands, changes in the printing industry, and so on, and so on. Moreover, they have to make sure that this knowledge is kept within their company and that they can apply it as well; a job that is extremely challenging in their dynamic industry. Thus, for Mark and Susan, it is important to manage their knowledge.

As this example shows, knowledge management (KM) is relevant for even an extremely small company like Measure \& Co. Equally, or perhaps even more so, $\mathrm{KM}$ is relevant for thousands and thousands of other small and medium sized enterprises (SMEs) all around the globe. In particular, SMEs in high-tech areas, characterized by complex and dynamic environments, are affected. However, if we look around us in the literature on KM, we see that most of it has a strong focus on large or even very large multi-national companies. Much has been written on, for example, knowledge strategies, intra- and interdepartmental knowledge sharing, KM information systems, and on $\mathrm{KM}$ in dispersed organizations. To what extent does this apply to Measure \& Co?

We see the bias towards large firms also in the development of commercial KM solutions. How should Measure \& Co make use of, for example, groupware, intranets, data mining, semantic networks, knowledge maps, and content management systems? Yet, for Mark and Susan there remains knowledge to manage.

This book addresses the challenges of managing knowledge in SMEs and in particularly those SMEs that operate in high-tech sectors. As illustrated in the example of Measure \& Co, these challenges are different than those for large companies, not the least because SMEs are much more dependent on their environment than many large companies. Therefore, this book introduces the concept of knowledge integration (KI), which consists of the identification, acquisition, and utilization of external knowledge. $\mathrm{KI}$ is different from $\mathrm{KM}$ in that it places much more emphasis on external knowledge than KM does.

As good KM and KI ensure that high-quality knowledge is applied successfully, this book aims to provide knowledge that is both of high quality and applicable. To this end, it provides many examples and cases from practice, but always with a thorough foundation in the literature. 
The book is not exclusively written for academics, nor is it exclusively written for practitioners. It rather aims at integrating both views. It is written by academics and practitioners together who attempted to learn from each other. As editors, we have extensively and successfully cooperated with the authors of the chapters in this book during a 3-year project 'Knowledge Integration and Network eXpertise' (KINX). This project was supported by the European Community under the "Competitive and Sustainable Growth" Programme.

In an attempt to impart our experiences to a wider audience we decided to publish our findings in this book. Drawing on a theoretical basis, it presents concepts and instruments that are designed to help SMEs to cope with their problems in identifying, acquiring and using external knowledge. We hope that it contributes to fill the current gap in useful books for KM in SMEs.

The editors

Antonie Jetter

Jeroen Kraaijenbrink

Hans-Horst Schröder

Fons Wijnhoven 


\section{Table of Contents}

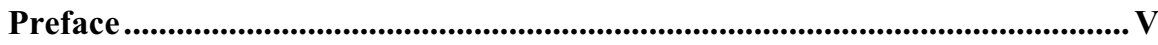

1 Knowledge Management: More than a Buzzword ..............................................1

Fons Wijnhoven

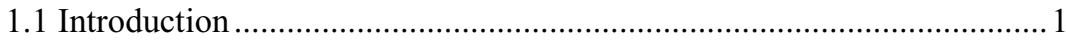

1.2 The Relevance of Knowledge Management for High-tech Small and Medium Sized Firms........................................................................... 2

1.3 Knowledge Management - What Is It About? ........................................ 3

1.3.1 Knowledge Management versus Competence Management..............3

1.3.2 Approaches to Knowledge Management ………………………....... 3

1.3.3 Levels of Knowledge Management ................................................. 5

1.4 What Aspects Are Related to Knowledge? ............................................. 6

1.4.1 Content in Knowledge Identification and Acquisition Processes ....7

1.4.2 Utilization of Knowledge in Contexts ............................................. 9

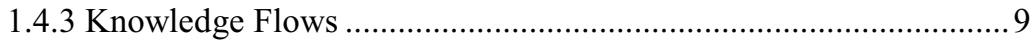

1.4.4 Knowledge Media ...................................................................... 10

1.5 The Knowledge Integration Context ……………………………...... 12

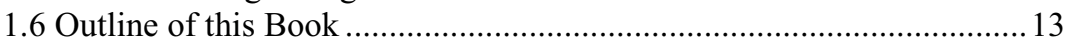

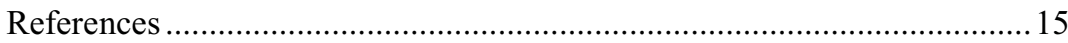

2 Knowledge Integration by SMEs - Framework ..................................................17

Jeroen Kraaijenbrink, Doron Faran, Aharon Hauptman

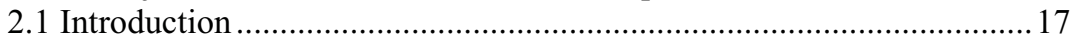

2.2 High-tech SMEs: Characteristics and Differences ………………….... 18

2.3 Types and Sources of Knowledge ....................................................... 19

2.4 KI Processes and Activities ..................................................................22

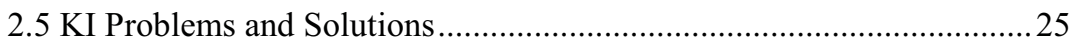

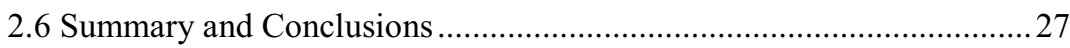

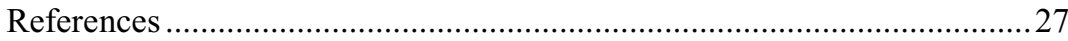

3 Knowledge Integration by SMEs - Practice ...................................................29

Jeroen Kraaijenbrink, Aard Groen, Fons Wijnhoven

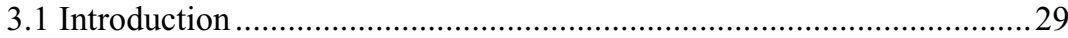

3.2 Analysing KI in SMEs: Research Framework …………………….....29

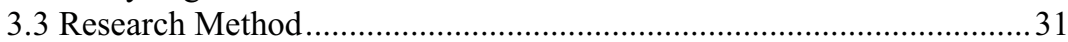

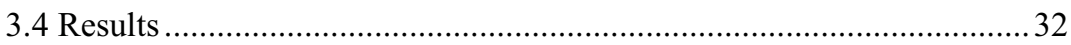

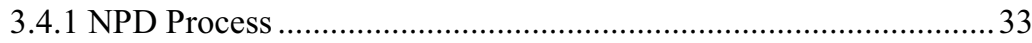

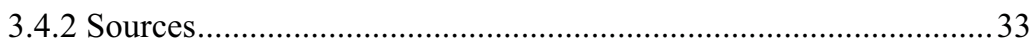

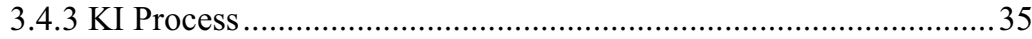

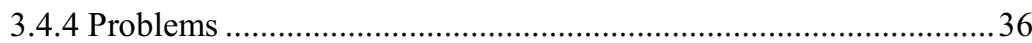

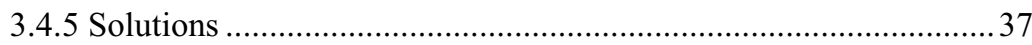

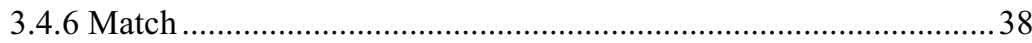




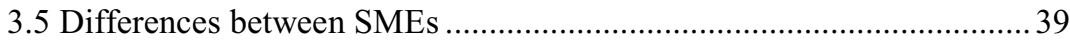

3.6 Conclusions and Implications ………………………......................... 41

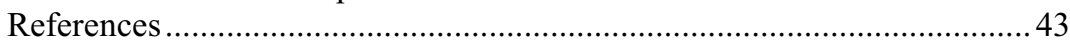

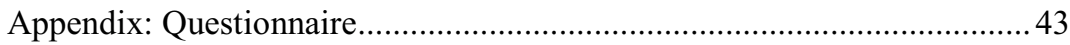

4 Organizing the Toolbox - Typology and Alignment of KI Solutions ............ 47

Doron Faran, Aharon Hauptman, Yoel Raban

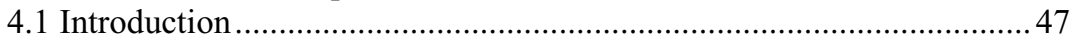

4.2 Definitions and Principles of the Typology ………………………....... 48

4.3 Typology of KI Tools and Techniques.................................................5 50

4.3.1 Activities for Latent Knowledge ...................................................51

4.3.2 Activities for Explicit Knowledge ..............................................52

4.3.3 Activities for Tacit Knowledge .....................................................58

4.3.4 Motivating Activities...................................................................58

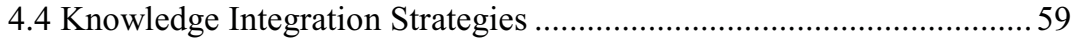

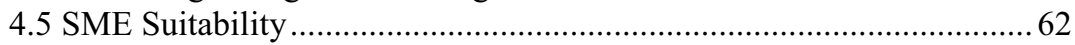

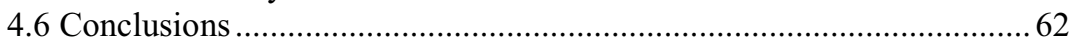

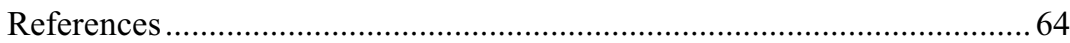

5 Elicitation - Extracting Knowledge from Experts .............................................65

Antonie Jetter

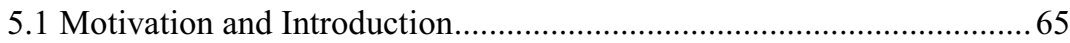

5.2 A Psychological Perspective on Knowledge Elicitation ..........................65

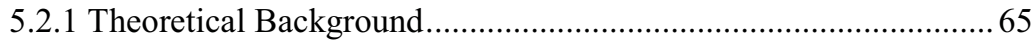

5.2.2 Relevance for Knowledge Management ......................................... 68

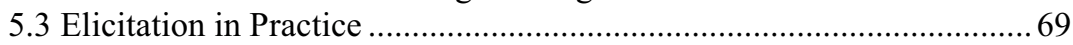

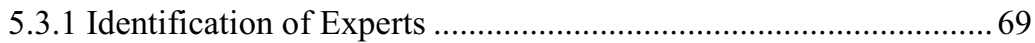

5.3.2 Activation and Capture of Knowledge........................................... 70

5.3.3 Knowledge Interpretation and Documentation ............................... 71

5.4 Implementation Experience................................................................ 72

5.4.1 Identification of Experts at CEROBEAR ……………………....... 73

5.4.2 Activation and Capture: Free Association \& Episodic Interviews. 73

5.4.3 Interpretation and Documentation: Building an Ontology..............74

5.5 Discussion and Conclusions................................................................ 75

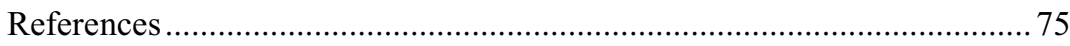

6 Codification - Knowledge Maps .............................................................................77

Antonie Jetter

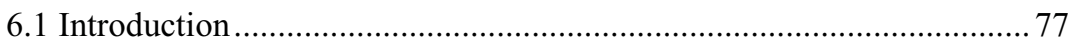

6.2 Knowledge Codification and Knowledge Maps...................................... 77

6.3 Types of Knowledge Maps ………………………………................. 79

6.3.1 Hierarchical or Radial Knowledge Structure Maps: .........................

Concept Maps and Mind Maps ............................................................... 80

6.3.2 Networked Knowledge Structure Maps: Causal Maps ................... 81

6.3.3 Knowledge Source Maps ........................................................... 82

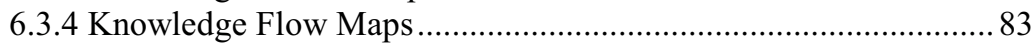


6.4 Case Study: Knowledge Maps to Improve NPD .............................. 85

6.4.1 Process Assessment .................................................................. 85

6.4.2 Improved Processes: AIXTRON's Knowledge Application Map 87

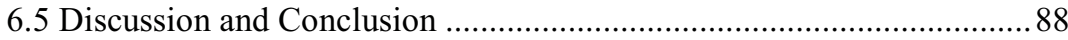

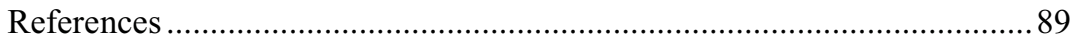

7 Detection - Electronic Knowledge Retrieval..................................................91

Dina Franzen

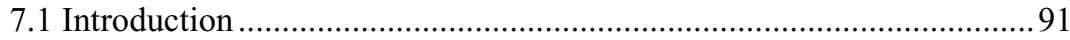

7.2 IR Systems for Knowledge Detection ..............................................91

7.2.1 Traditional IR Search Methods .................................................. 92

7.2.2 Information Retrieval and the WWW .......................................93

7.2.3 New Impulses in IR Systems ................................................... 94

7.3 Implementation at a High-tech SME .................................................96

7.3.1 The High-tech SME: CEROBEAR ..............................................96

7.3.2 Focus: Development of a Customer-Specific Ontology ............... 97

7.3.3 Results and Evaluation.............................................................. 98

7.4 Discussion and Conclusion ........................................................... 99

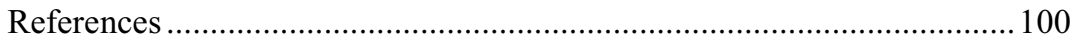

8 Assessment - Making Sense of It All .............................................................. 101

Doron Faran

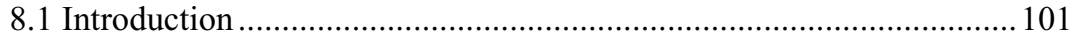

8.2 What Is Knowledge Assessment? ....................................................... 102

8.3 Critical Analysis of Assessment Practices......................................... 103

8.3.1 Theoretical Background and Practical Framework..................... 103

8.3.2 Alignment of Available Practices ............................................. 104

8.4 The Decision-Validity-Tracking (DVT) Method ................................ 105

8.5 Lessons Learned from the Implementation at Optibase ..................... 110

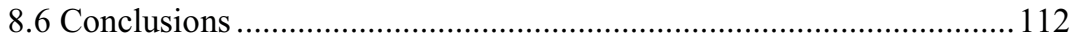

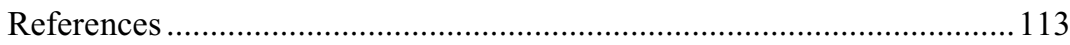

9 Transfer - Knowledge Transfer in Networks .............................................115

Aard Groen

9.1 Introduction ................................................................................. 115

9.2 Theory on Knowledge Transfer in NPD Processes .......................... 115

9.2.1 The Character of Knowledge and Networks in Transfer

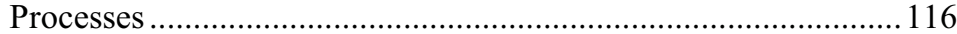

9.2.3 Some Consequences of Cognitive Distance for Networking of

Small Firms ............................................................................. 117

9.3 The WAP Project, an Example of Knowledge Transfer in a Network 119

9.3.1 Context of the Project ............................................................. 119

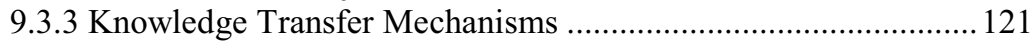

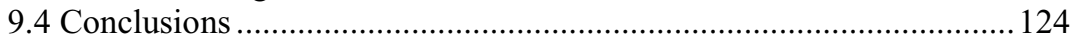

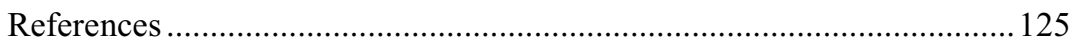


10 Motivating - Incentive Systems for Knowledge Provision.

Hannah Zaunmüller

10.1 Introduction

10.2 Design Areas of Incentive Systems for Knowledge Provision.......... 128

10.2.1 Definition of Knowledge Goals ................................................. 128

10.2.2 Definition of the Application Area .......................................... 129

10.2.3 Definition of Incentive Tools.................................................... 129

10.2.4 Measurement and Evaluation of Employee Performance .......... 130

10.3 Implementation of Incentive Systems ........................................ 130

10.3.1 Analysis of the Status-quo ....................................................... 130

10.3.2 Concept Development and Elaboration ................................... 132

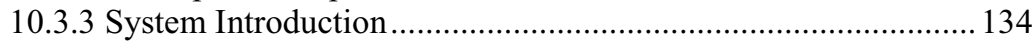

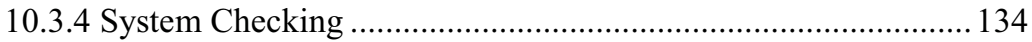

10.4 Case Study at HEAD Acoustics ...................................................... 135

10.4.1 HEAD Acoustics and the Focus of the Project .......................... 135

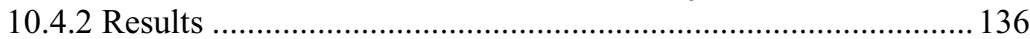

10.5 Summary and Conclusion ............................................................. 140

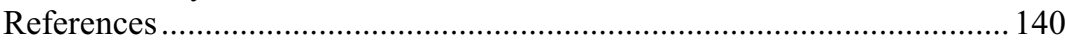

11 Supporting Knowledge Integration at SMEs - The KINX Portal ........... 143

Charo Elorrieta, Juan Pedro Lopez, Fons Wijnhoven

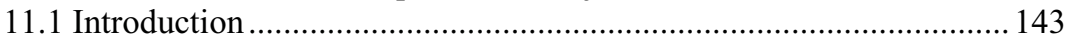

11.2 Information Services and Scope of the KINX Portal ....................... 145

11.3 Knowledge Integration Portal Description...................................... 146

11.3.1 The KINX Portal Public Area..................................................... 148

11.3.2 The Private Area ..................................................................... 150

11.3.3 The Administration Area ........................................................ 155

11.4 Portal Development Process............................................................. 156

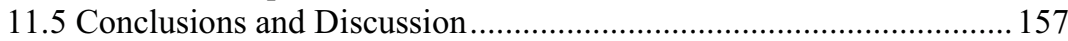

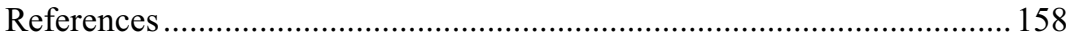

12 Supporting Knowledge Integration at SMEs - Policies ........................... 161

Yoel Raban

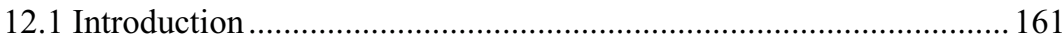

12.2 Reasons for Supporting KI in SMEs ............................................. 161

12.3 Profiles of KI Support Measures for SMEs..................................... 162

12.4 Usage of Selected KI Support Measures .......................................... 167

12.5 The Effectiveness of KI Support Measures......................................... 168

12.6 Summary and Recommendations ................................................... 172

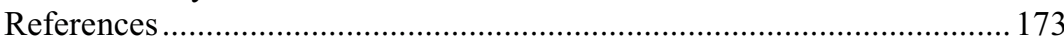




\section{Wrapping It All Up - Past, Present and Future of Knowledge}

Integration.

Hans-Horst Schröder

13.1 Introduction

13.2 Evaluation of KI - What Does It Promise and Does It Keep What It Promises?

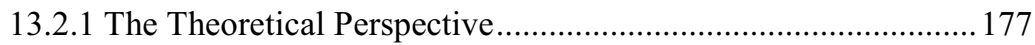

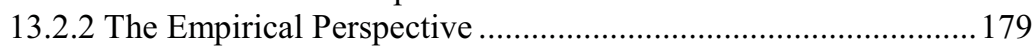

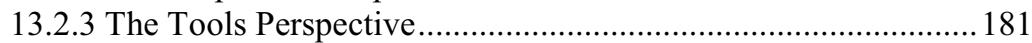

13.3 The Further Development of KI Requirements and Opportunities

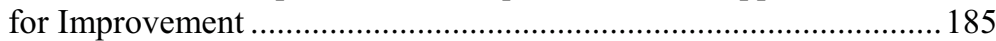

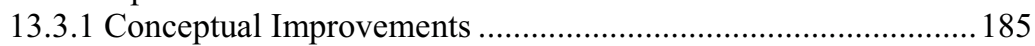

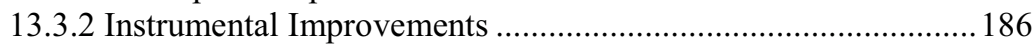

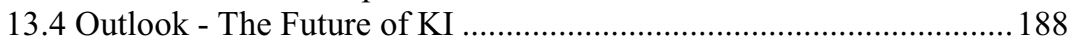

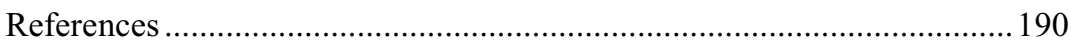

Biographical Information about the Authors .....................................................193

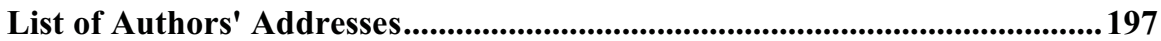

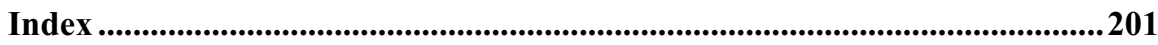

